\title{
LC-UV method to assay raloxifene hydrochloride in rat plasma and its application to a pharmacokinetic study
}

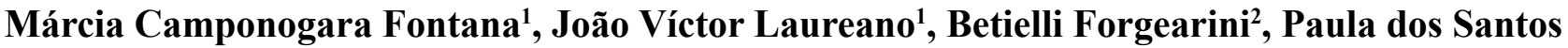 \\ Chaves $^{1}$, Bibiana Verlindo de Araujo ${ }^{1}$, Ruy Carlos Ruver Beck ${ }^{*}$
}

\begin{abstract}
${ }^{1}$ PPG em Ciências Farmacêuticas, Faculdade de Farmácia, Universidade Federal do Rio Grande do Sul (UFRGS), Porto Alegre, Rio Grande do Sul, Brazil, ${ }^{2}$ Faculdade de Farmácia, Universidade Federal do Rio Grande do Sul (UFRGS), Porto Alegre, Rio Grande do Sul, Brazil
\end{abstract}

\begin{abstract}
A specific, precise, and accurate LC-UV method was developed and validated to assay raloxifene hydrochloride in rat plasma. Raloxifene was analyzed after liquid-liquid extraction and quantified by reversed phase liquid chromatography (C18 column) using acetonitrile and ammonium acetate buffer $0.05 \mathrm{M}(\mathrm{pH} 4.0)$ as mobile phase at a flow rate of $1 \mathrm{~mL} \cdot \mathrm{min}^{-1}$ and UV detection at $287 \mathrm{~nm}$. Retention times of raloxifene and internal standard (dexamethasone) were approximately $11 \mathrm{~min}$ and $14 \mathrm{~min}$, respectively. Linearity was checked for a concentration range between $25 \mathrm{ng} \cdot \mathrm{mL}^{-1}$ and $1000 \mathrm{ng} \cdot \mathrm{mL}^{-1}$. Intra- and inter-day precision had relative standard deviation lower than $10 \%$ and $15 \%$, respectively. Recovery from plasma was higher than $90 \%$. Accuracy values were $98.21 \%, 99.70 \%$, and $102.70 \%$ for lower, medium, and upper limits of quantification, respectively. Limit of quantification was $25 \mathrm{ng} \cdot \mathrm{mL}^{-1}$. Drug stability was analyzed at room temperature using plasma kept in a freezer at $-80{ }^{\circ} \mathrm{C}$ for 45 days after processing for $6 \mathrm{~h}$ and three freeze-thaw cycles. The advantages of the method developed include stability under different conditions and low limit of quantification. Its applicability was confirmed by the analysis of raloxifene levels in plasma samples in a designed pharmacokinetic study in rats after intravenous administration $\left(5 \mathrm{mg} \cdot \mathrm{kg}^{-1}\right)$.
\end{abstract}

Keywords: Raloxifene/pharmacokinetic; Liquid chromatography. Plasma. Bioavailability.

\section{INTRODUCTION}

Characterized by reduced bone mass, osteoporosis affects women in the menopausal period. Raloxifene hydrochloride ( $\left.\mathrm{RH} ; \mathrm{C}_{28} \mathrm{H}_{27} \mathrm{NO}_{4} \mathrm{~S} . \mathrm{HCl}\right)$ is a selective estrogen receptor modulator with agonist effect on bones. It is usually administered to women for the prevention and treatment of osteoporosis (Morello, Wurz, DeGregorio, 2003; Kayath, 1999). A 60-mg RH tablet is administered orally, when $60 \%$ of the dose is absorbed from the gastrointestinal tract and reaches absolute bioavailability of mere 2\% (Morello, Wurz, DeGregorio, 2003). With an extensive intestinal and hepatic metabolism, RH has a half-life of $28 \mathrm{~h}$ (Kosaka et al., 2011; Jeong et al., 2005). The compound is extensively distributed in the body.

\footnotetext{
*Correspondence: R. C. R. Beck. Faculdade de Farmácia, Universidade Federal do Rio Grande do Sul. Av. Ipiranga 2752, Bairro Santana, CEP 90610-000, Porto Alegre, RS, Brazil. Tel: +55 5133085951 / Fax: +55 51 33085090. E-mail address: ruy.beck@ufrgs.br (i)
}

Volume of distribution is not dose-dependent, and $\mathrm{RH}$ is highly bound to plasma proteins [98-99\%] (Morello, Wurz, DeGregorio, 2003; Hochner-Celnikier, 1999). Most of the RH dose administered and the main part of its glucoronide metabolites are excreted in feces (HochnerCelnikier, 1999).

The quantification of RH in plasma has been described using different techniques, such as capillary electrophoresis (Pérez-Ruiz, 2004), liquid chromatography coupled to mass spectrometry (Trontelj et al., 2007), and ultra performance liquid chromatography (Jadhav, Ramaa, 2012). Few articles have discussed the development and validation of an analytical method for the quantification of RH in rat plasma using liquid chromatography with ultraviolet detection (LC-UV). Nevertheless, the applicability of this technique has been investigated in the quantification of RH in drug dosage forms (Salazar et al., 2015). Yang et al. (2007) validated a LC-UV method to determine raloxifene in rat plasma in a pharmacokinetic study, reporting a limit of quantification of $0.20 \mu \mathrm{g} \cdot \mathrm{mL}^{-1}$ 
using $23{ }^{\circ} \mathrm{C}$ as column temperature. On the other hand, Chen et al. (2010) conducted a RH pharmacokinetic study in rats based on a LC-UV method using a gradient elution of the mobile phase and a limit of quantification of 0.56 $\mu \mathrm{g} . \mathrm{mL}^{-1}$. However, to the best of our knowledge, simple and inexpensive pharmacokinetic analytical methods with low limits of quantification and excellent accuracy for the analysis of RH in biological samples have not been designed. In addition, Ravi, Aditya and Vats (2012) developed a LC-UV method to estimate RH levels in rabbit plasma with a limit of quantification of $0.05 \mu \mathrm{g} \cdot \mathrm{mL}^{-1}$. It is important to highlight that these methods (Yang et al., 2007; Chen et al., 2010; Ravi, Aditya, Vats, 2012) were based on a protein precipitation technique to extract the drug from rat or rabbit plasma.

In this scenario, the aims of this study were to develop and validate an analytical LC-UV method based on liquid-liquid technique to extract the drug from rat plasma. This approach was proposed to afford low limits of quantification to assay $\mathrm{RH}$ in rat plasma, considering the requirements for suitable application in a pharmacokinetic study after RH intravenous administration.

\section{MATERIAL AND METHODS}

\section{Material}

Briefly, RH was obtained from Sequoia Research Products (Oxford, United Kingdom). Dexamethasone (internal standard - IS) was donated by Multilab Industry of Pharmaceutical Products Ltda (São Jerônimo, Brazil). Ammonium acetate was supplied by Stilolab Products for Laboratory (Porto Alegre, Brazil). Acetonitrile and methyl tert-butyl ether (MTBE) HPLC grade were purchased from Tedia (Rio de Janeiro, Brazil).

\section{Apparatus and chromatographic conditions}

An HPLC apparatus was used to carry out the validation study. The system consisted of a liquid chromatograph (10AD model, Shimadzu, Japan) with a SPD-M20AV detector, a degasser DGU-20A5, a CBM20A controller, a LC-20AT pump, and a SIL-20A auto sampler. Chromatographic separation was performed in a C18 column $(150 \mathrm{~mm} \times 4.6 \mathrm{~mm}, 5-\mu \mathrm{m}$ particle size, 110-Å pore diameter; Discovery ${ }^{\circledR}$, Supelco Analytical, Sigma-Aldrich) and a mobile phase composed of acetonitrile $95 \%$ and $0.05 \mathrm{M}$ ammonium acetate (28:72 $\mathrm{v} / \mathrm{v}$ ) containing $0.2 \%$ glacial acetic acid at isocratic flow rate $\left(1.0 \mathrm{~mL} \cdot \mathrm{min}^{-1}\right)$. The mobile phase was filtered using a membrane $\left(0.45 \mu \mathrm{m}\right.$, Millipore $\left.^{\circledR}\right)$ and a vacuum pump, and degassed before use. The analysis was performed for 18 $\mathrm{min}$ at $287 \mathrm{~nm}$ with injection volume of $40 \mu \mathrm{L}$. The ratio of peak area of RH to IS was used for the quantification of plasma samples.

\section{Preparation of standard solutions}

A RH stock solution was prepared dissolving 12.5 $\mathrm{mg}$ of the drug in methanol in a volumetric flask $(25 \mathrm{~mL})$ to a final concentration of $0.5 \mathrm{mg} \cdot \mathrm{mL}^{-1}$. This solution was stored in a freezer at $-80^{\circ} \mathrm{C}$ and was diluted with mobile phase to obtain a $50.0 \mu \mathrm{g} . \mathrm{mL}^{-1}$ solution, immediately before use. Working standard solutions were prepared daily by serial dilution of the solution at $50.0 \mu \mathrm{g} . \mathrm{mL}^{-1}$ with the mobile phase to obtain analyte concentrations of $0.25,0.50,1.00,2.50,5.00$, and $10.00 \mu \mathrm{g} \cdot \mathrm{mL}^{-1}$. The internal standard (dexamethasone) working solution was prepared in methanol to yield a concentration of $0.50 \mathrm{mg} \cdot \mathrm{mL}^{-1}$ and diluted to $100.0 \mu \mathrm{g} . \mathrm{mL}^{-1}$ immediately before use.

The quality control plasma samples (QC) were prepared from a different stock solution from that used to generate the analytical curve samples using working standard solutions at $0.35,4.50$, and $9.00 \mu \mathrm{g} . \mathrm{mL}^{-1}$. These samples were used to evaluate intra- and inter-day variations.

\section{Standard solutions in plasma}

The samples of analytical curves $(25.0,50.0,100.0$, 250.0, 500.0, and 1,000 ng. $\mathrm{mL}^{-1}$ ) were prepared using 90 $\mu \mathrm{L}$ of blank rat plasma with $10 \mu \mathrm{L}$ of internal standard and $10 \mu \mathrm{L}$ of working standard solutions. The final concentration of internal standard was $10 \mu \mathrm{g} \cdot \mathrm{mL}^{-1}$.

\section{Sample preparation}

Plasma samples were stored in a freezer at $-80{ }^{\circ} \mathrm{C}$ upon analysis (for approximately 45 days). The liquidliquid technique was used to extract the drug from plasma. In an Eppendorf tube, $10 \mu \mathrm{L}$ of internal standard was added to $100 \mu \mathrm{L}$ of plasma samples, followed by vortex mixing for $5 \mathrm{~s}$. The organic solvent MTBE $(500 \mu \mathrm{L})$ was added for the extraction. Samples were shaken (10 $\mathrm{min})$ and centrifuged $\left(6800 \mathrm{~g}\right.$ for $10 \mathrm{~min}$ at $\left.4{ }^{\circ} \mathrm{C}\right)$. The supernatants were transferred to tubes for evaporation of the organic solvent in a centrifuge at $40{ }^{\circ} \mathrm{C}$. The pellets were resuspended with mobile phase $(100 \mu \mathrm{L})$, stirred for $5 \mathrm{~s}$ (vortex mixing), sonicated for $10 \mathrm{~min}$, and assayed following the LC-UV method described above. 


\section{Bioanalytical method validation}

The method was validated according to the FDA Guidance - Bioanalytical Method Validation (2001) considering linearity, lower limit of quantification, specificity, precision, accuracy, and stability.

\section{Linearity, lower limit of quantitation and specificity}

To analyze linearity, six analytical curves prepared using six plasma concentrations in the range of 25.0 ng. $\mathrm{mL}^{-1}$ to $1,000 \mathrm{ng} . \mathrm{mL}^{-1}(25.0,50.0,100.0,250.0,500.0$, and $1,000 \mathrm{ng} \cdot \mathrm{mL}^{-1}$ ) were assayed on two consecutive days. The drug was extracted from the biological samples and resuspended in $100 \mu \mathrm{L}$ of the mobile phase according to the technique described in the "Sample preparation" section, followed by the LC-UV analysis. Each analytical curve was plotted using the average relative area of each concentration of the curve (peak area of $\mathrm{RH} /$ peak area of IS). The six concentrations of the standard solution were analyzed by linear regression to calculate the equation of the calibration curve and correlation coefficients. The lowest concentration of the analytical curve with acceptable precision and accuracy was considered the limit of quantification. Specificity of the method was analyzed assaying six blank plasma samples from rats.

\section{Precision and accuracy}

Intra- and inter-day precision as well as accuracy of the analytical method were determined calculating the standard deviation (SD) and relative standard deviation (RSD\%) of three concentrations (low, medium, and high) in six replicate analysis. Samples were prepared with 80 $\mu \mathrm{L}, 10 \mu \mathrm{L}$ of the internal standard solution $\left(10 \mu \mathrm{g} . \mathrm{mL}^{-1}\right)$, and $10 \mu \mathrm{L}$ of RH standard solution. The drug was extracted and resuspended in $100 \mu \mathrm{L}$ of the mobile phase to reach concentrations of 35.0, 450.0, and $900 \mathrm{ng} . \mathrm{mL}-1$ of RH as described above.

\section{Recovery}

Relative recovery was analyzed comparing the analytical results of extracted samples from three concentrations $\left(35.0,450.0\right.$, and $\left.900 \mathrm{ng} . \mathrm{mL}^{-1}\right)$ with those obtained from standard solution that is $100 \%$ of recovery.

\section{Stability}

The stability of RH in rat plasma was performed using the low (35 ng. $\left.\mathrm{mL}^{-1}\right)$ and high (900 ng. $\left.\mathrm{mL}^{-1}\right)$ concentrations. The samples were analyzed in the shortterm ( $6 \mathrm{~h}$ on the workbench) after processing $(6 \mathrm{~h}$ in autosampler), after three freeze-thaw cycles, and after long-term storage in freezer at $-80{ }^{\circ} \mathrm{C}$ (45 days).

\section{Pharmacokinetic study}

A pilot pharmacokinetic study was performed using male Wistar rats $(n=3)$, and the analytical method validated was evaluated to determine $\mathrm{RH}$ plasma concentration. The experiment was performed according to the Severity Guide of Scientific Procedures and as approved by Ethics Committee on Animal Use of the Federal University of Rio Grande do Sul (Protocol number 22226).

Three rats $(250-350 \mathrm{~g})$ were purchased from the Center for Reproduction and Experimentation of Laboratory Animal of Federal University of Rio Grande do Sul. The animals were exposed to daily 12-h dark-light cycles in a room with controlled temperature $\left(22 \pm 1^{\circ} \mathrm{C}\right)$, relative humidity of approximately $65 \%$, and were offered water and food ad libitum.

On the day of the experiment, rats were anesthetized with urethane $\left(1.25 \mathrm{~g} . \mathrm{kg}^{-1}\right)$ and the carotid artery was exposed for cannulation and subsequent blood collection $(200 \mu \mathrm{L})$. A solution of RH $\left(2.5 \mathrm{mg} \cdot \mathrm{mL}^{-1}\right)$ was prepared dissolving $12.5 \mathrm{mg}$ of drug in $5 \mathrm{~mL}$ of glucose solution containing $5 \%$ of dimethylsulfoxide. This solution was administere as a $5-\mathrm{mg} \cdot \mathrm{kg}^{-1}$ intravenous dose in the femoral vein.

Blood samples were collected at time zero (before administration of drug) and 0.08, 0.17, 0.25, 0.5, 1.0, $3.0,6.0,9.0$, and $12.0 \mathrm{~h}$ after intravenous administration. Samples were centrifuged at $4{ }^{\circ} \mathrm{C}$ to separate the plasma $(6800 \mathrm{~g}$ for $10 \mathrm{~min})$ and stored in a freezer $\left(-80^{\circ} \mathrm{C}\right)$ upon analysis using the validated method described above. Plasma pharmacokinetic profiles of RH were analyzed by non-compartment approach using the Phoenix ${ }^{\circledR}$ Software (Certara, 2015, USA).

\section{RESULTS AND DISCUSSION}

Chromatograms of blank rat plasma and rat plasma containing RH (500 ng. $\left.\mathrm{mL}^{-1}\right)$ with internal standard (10 $\left.\mu \mathrm{g} . \mathrm{mL}^{-1}\right)$ are shown in Figure 1. The chromatograms confirm specificity of the method, since it was possible to separate $\mathrm{RH}$ and internal standard peaks from endogenous substances of plasma. The mean retention times of RH and internal standard were approximately $11 \mathrm{~min}$ and $14 \mathrm{~min}$, respectively. Endogenous substances were detected until $9 \mathrm{~min}$ into the run time of $18 \mathrm{~min}$.

The mean analytical curve (25-1000 ng. $\left.\mathrm{mL}^{-1}\right)$ showed adequate linearity $(\mathrm{r}=0.9986 \pm 0.0012)$, angular coefficient (slope) of $0.0017 \pm 0.0001$, and an intercept of $0.0190 \pm 0.0167$. The limit of quantification was set at $25 \mathrm{ng} \cdot \mathrm{mL}^{-1}$ of RH (which showed intra- and inter- 

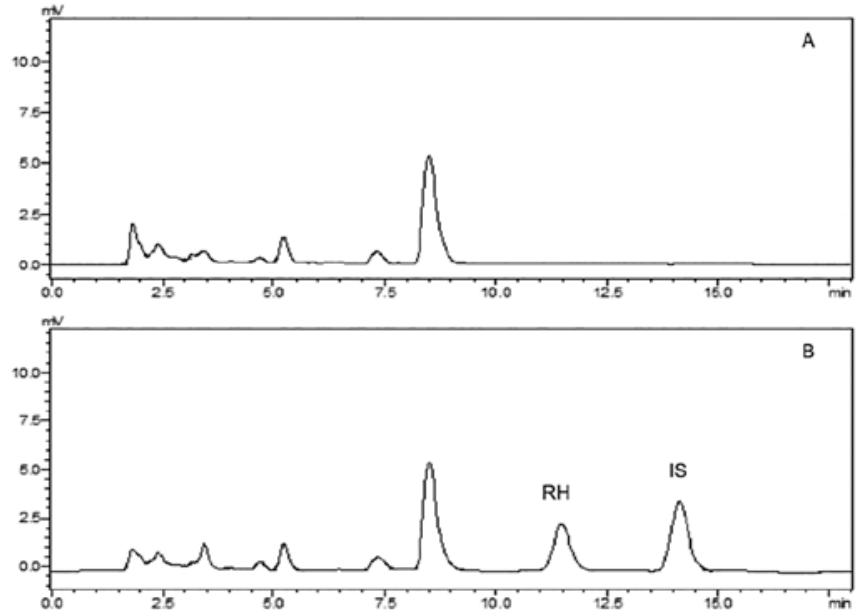

FIGURE 1 - Chromatogram obtained for (A) blank plasma, (B) blank plasma with raloxifene hydrochloride at $500 \mathrm{ng} \cdot \mathrm{mL}^{-1}$ (RH), and internal standard $10 \mu \mathrm{g} \cdot \mathrm{mL}^{-1}-$ (IS).

day imprecision of $10.01 \%$ and $14.08 \%$, respectively), accuracy of $96.19 \pm 7.03 \%$, and a recovery of $90.12 \pm$ $5.34 \%$. These values are in agreement with the FDA guidelines (FDA Guidance - Bioanalytical Method Validation, 2001). Moreover, this limit of quantification value was lower than other limits of quantification previously reported in the literature for the RH assay in biological samples by LC-UV methods (Yang et al., 2007; Chen et al., 2010; Ravi, Aditya, Vats, 2012), which can be explained considering the liquid-liquid extraction technique used in this study, compared with the methods of simple protein precipitation from rat (Yang et al., 2007; Chen et al., 2010) or rabbit (Ravi, Aditya, Vats, 2012) plasma used in previous studies.

Table I shows the results of precision (RSD), accuracy $(\%)$, and recovery (\%) obtained in the analysis of samples containing RH $35 \mathrm{ng} \cdot \mathrm{mL}^{-1}, 450 \mathrm{ng} \cdot \mathrm{mL}^{-1}$, and $900 \mathrm{ng} \cdot \mathrm{mL}^{-1}$ (low, medium, and high concentration, respectively).

The RSD results, comprising repeatability (intraday precision), and intermediate precision (inter-day precision) were lower than $10 \%$ and $15 \%$, respectively. Accuracy was approximately $100 \%$. Recovery, which represents extraction efficiency, was higher than $90 \%$ for the three concentrations, in accordance with previous reports (Yang et al., 2007). These results also agree with International Guidelines (FDA Guidance - Bioanalytical Method Validation, 2001).

The stability of the samples was studied according to the working conditions, using RH concentrations of 35 ng. $\mathrm{mL}^{-1}$ and 900 ng. $\mathrm{mL}^{-1}$. The results are shown in Table II. The maximum RSD of $8 \%$ demonstrates the stability of the analyte throughout sample processing. These results confirmed all requirements for a bioanalytical method according to international guidelines. Therefore, the method developed was tested again in a $\mathrm{RH}$ pharmacokinetic study in order to highlight its importance and contribution to pharmacokinetics.

TABLE I - Intra- and inter-day precision (RSD), accuracy (mean $\pm \mathrm{SD}$ ) and relative recovery (mean $\pm \mathrm{SD}$ ) for the RH quality controls in rat plasma $(n=6)$

\begin{tabular}{ccccc}
\hline $\begin{array}{c}\text { Concentration } \\
\left.\text { (ng.mL } \mathbf{m}^{-1}\right)\end{array}$ & $\begin{array}{c}\text { Intra-day precision } \\
\text { (RSD, \%) }\end{array}$ & $\begin{array}{c}\text { Inter-day precision } \\
\text { (RSD, \%) }\end{array}$ & Accuracy (\%) & Recovery (\%) \\
\hline 35 & 9.68 & 14.84 & $98.21 \pm 8.49$ & $91.45 \pm 4.62$ \\
450 & 2.44 & 7.97 & $99.70 \pm 7.89$ & $94.21 \pm 3.38$ \\
900 & 8.87 & 8.62 & $102.70 \pm 8.76$ & $92.10 \pm 6.53$ \\
\hline
\end{tabular}

TABLE II - Stability of RH in rat plasma at two quality control levels $(\mathrm{n}=3)$

\begin{tabular}{lccc}
\hline Condition & Concentration $\left(\mathbf{n g . m L} \mathbf{L}^{-\mathbf{1}}\right)$ & RH content \pm SD (\%) & RSD (\%) \\
\hline \multirow{2}{*}{ Short-term } & 35 & $100.52 \pm 4.66$ & 4.64 \\
& 900 & $104.83 \pm 8.39$ & 8.00 \\
\hline \multirow{2}{*}{ Autosampler } & 35 & $99.26 \pm 4.00$ & 4.03 \\
& 900 & $100.08 \pm 5.98$ & 6.12 \\
\hline \multirow{2}{*}{ Freeze-thaw } & 35 & $101.74 \pm 5.90$ & 6.09 \\
\hline \multirow{2}{*}{ Long-term } & 900 & $97.05 \pm 7.18$ & 7.46 \\
\hline
\end{tabular}


Figure 2 shows the plasma pharmacokinetic profile after intravenous administration of RH $5 \mathrm{mg} \cdot \mathrm{kg}^{-1}$ $(\mathrm{n}=3)$. A rapid distribution of the drug from plasma was observed. The pharmacokinetic parameters obtained after non-compartmental analysis were: $\mathrm{AUC}_{0-\infty}=1924.32$ \pm 264.42 ng.h. $\mathrm{mL}^{-1}, \lambda=0.20 \pm 0.01 \mathrm{~h}^{-1}, \mathrm{t}_{1 / 2}=3.45 \pm$ $0.23 \mathrm{~h}, \mathrm{MRT}=4.52 \pm 0.17 \mathrm{~h}, \mathrm{CL}=2.94 \pm 0.43 \mathrm{~L} . \mathrm{kg} \cdot \mathrm{h}^{-1}$, Vdss $=13.26 \pm 1.36 \mathrm{~L} . \mathrm{Kg}^{-1}$. Furthermore, the analytical method showed sufficient sensitivity to detect very low RH plasma concentration, even at the last phase of the pharmacokinetic profile, when as little as $25 \mathrm{ng} . \mathrm{mL}^{-1}$ of drug was quantified. It would not be able to be detect such a low concentration of RH using LC-UV methods previously described in the literature to estimate the amounts of the drug in plasma.

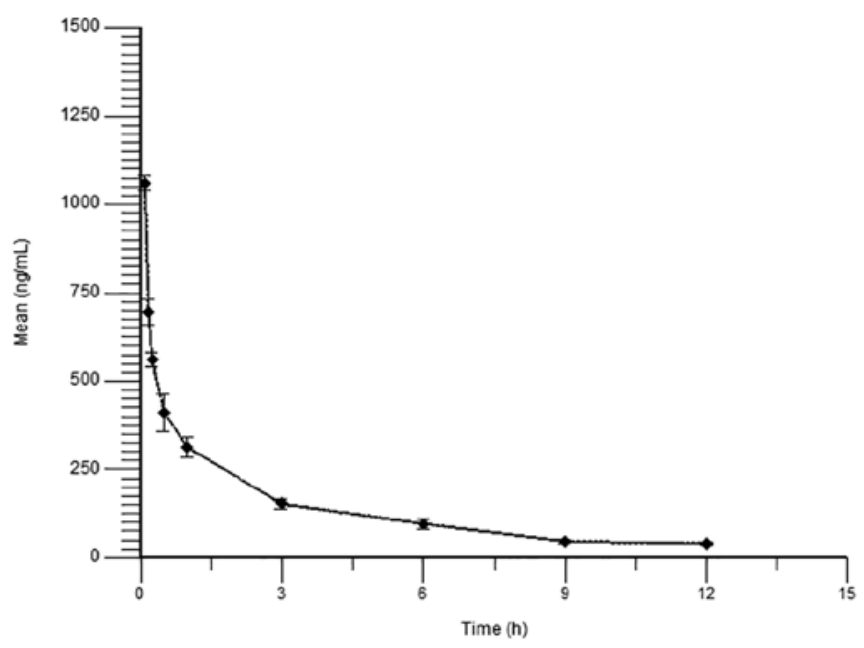

FIGURE 2 - Mean plasma concentration-time profile of RH after intravenous administration of $5 \mathrm{mg} \cdot \mathrm{kg}^{-1} \mathrm{drug}$. Data are expressed as mean $\pm \operatorname{SD}(n=3)$.

The lack of methods with low limits of quantification of $\mathrm{RH}$ in rat plasma may be the reason why previous pharmacokinetic studies evaluated only relative bioavailability (Yang et al., 2007; Chen et al., 2010) due to the methodological restrictions to assay $\mathrm{RH}$ in the last phase.

\section{CONCLUSION}

A method to assay $\mathrm{RH}$ in rat plasma for application to pharmacokinetic studies was developed and validated using LC-UV and a liquid-liquid technique to extract the drug from plasma. This method showed good accuracy, linearity, specificity, and precision, and was successfully used to analyze rat plasma samples in a pilot pharmacokinetic study. The validated method has notable advantages, like the lower limit of quantitation compared with other LC-UV methods previously described in the literature, a good resolution between the analyte and the plasma components, and RH stability under different conditions. The present analytical method is suitable for use in pharmacokinetic studies that require the quantification of very low concentrations of drug in plasma, such as studies involving the development of innovative formulations containing $\mathrm{RH}$.

\section{ACKNOWLEDGEMENTS}

M.C. Fontana and P.S. Chaves are grateful to CAPES-Brazil for their PhD fellowships and J.V. Laureano for his MSc fellowship. B. Forgearini thanks $\mathrm{CNPq}$ for her scholarship. The authors acknowledge the financial support from .from CAPES (Finance Code 001), CNPq, FAPERGS, PRONEM/FAPERGS and PRONEX FAPERGS/CNPq, Rede Nanobiotec/CAPES. The drug was bought and kindly provided to the study by Silvia $\mathrm{S}$. Guterres/CNPq 307321/2009-6.

\section{REFERENCES}

Chen Y, Jia X, Chen J, Wang J, Hu M. The pharmacokinetics of raloxifene and its interaction with apigenin in rat. Molecules. 2010;15(11):8478-87.

Food and Drug Administration. FDA Guideline. United State, Food and Drug Administration, Center for Drug Evaluation and Research, Guidance - Bioanalytical Method Validation, 2001. Available from: http://www.fda.gov/downloads/Drugs/ Guidance/ComplianceRegulatoryInformation/Guidances/ UCM070107.pdf.

Hochner-Celnikier D. Pharmacokinetics of raloxifene and its clinical application. Eur J Obstet Gynecol Reprod Biol. 1999;85(1):23-29.

Jadhav DH, Ramaa CS. Development and validation of a UPLCMS/MS assay for simultaneous estimation of raloxifene and its metabolites in human plasma. J Bioanal Biomed. 2012;4:61-67.

Jeong EJ, Liu Y, Lin H, Hu M. Species- and disposition modeldependent metabolism of raloxifene in gut and liver: role of UGT1A10. Drug Metab Dispos. 2005;33(6):785-94.

Kayath MJ. Raloxifeno e osteoporose: revisão de um novo modulador seletivo do receptor de estrógeno. Arq Bras Endocrinol. 1999;43(6):433-41. 
Kosaka K, Sakai N, Endo Y, Fukuhara Y, Tsuda-Tsukimoto $\mathrm{M}$, Ohtsuka T, et al. Impact of intestinal glucuronidation on the pharmacokinetics of raloxifene. Drug Metab Dispos. 2011;39(9):1495-502.

Morello KC, Wurz GT, DeGregorio MW. Pharmacokinetics of selective estrogen receptor modulators. Clin Pharmacokinet. 2003;42(4):361-72.

Pérez-Ruiz T, Martinez-Lozano C, Sanz E, Bravo AJ. Development and validation of a quantitative assay for raloxifene by capillary electrophoresis. Pharmaceut Biomed. 2004;34(5):891-97.

Ravi PR, Aditya N, Vats R. Development, validation and pharmacokinetic application of liquid chromatographic method for estimation of raloxifene hydrochloride in rabbit plasma. Acta Chromatogr. 2012;24(4):559-73.
Salazar FR, Codevilla CF, Meneghini L, Bergold AM. Development of alternative methods for the determination of raloxifene hydrochloride in tablet dosage form. Braz J Pharm Sci 2015;51(2):349-360.

Trontelj J, Bogataj M, Marc J, Mrhar A. Development and validation of a liquid chromatography-tandem mass spectrometry assay for determination of raloxifene and its metabolites in human plasma. J Chromatogr B. 2007;855(2):220-7.

Yang ZY, Ahang ZHF, He XB, Zhaoo GY, Ahang YQ. Validation of a novel HPLC method for the determination of raloxifene and its pharmacokinetics in rat plasma. Chromatographia 2007;65:197-201.

Received for publication on $01^{\text {st }}$ February 2018 Accepted for publication on $22^{\text {nd }}$ April 2018 